\title{
Prevalence of Asymptomatic Recurrences of Atrial Fibrillation After Successful Radiofrequency Catheter Ablation
}

\author{
HAKAN ORAL, M.D., SRIKAR VEERAREDDY, M.D., ERIC GOOD, D.O., BURR HALL, M.D., \\ PETER CHEUNG, M.D., KAMALA TAMIRISA, M.D., JIHN HAN, M.D., JACKIE FORTINO, R.N., \\ AMAN CHUGH, M.D., FRANK BOGUN, M.D., FRANK PELOSI JR., M.D., \\ and FRED MORADY, M.D.
}

From the Division of Cardiology, University of Michigan, Ann Arbor, Michigan, USA

\begin{abstract}
Asymptomatic Atrial Fibrillation. Introduction: The long-term efficacy of radiofrequency catheter ablation of atrial fibrillation (AF) has been based on patient-reported symptoms suggestive of AF. However, asymptomatic recurrences of AF may remain undetected. The aim of this study was to determine the prevalence of asymptomatic recurrences of $\mathrm{AF}$ after an apparently successful catheter ablation procedure for AF.

Methods and Results: Among 244 consecutive patients (mean age $53 \pm 11$ years) who underwent a pulmonary vein isolation procedure for symptomatic paroxysmal AF and who reported no symptoms of recurrent $\mathrm{AF}$ at $\geq 6$ months after the procedure, 60 patients with a history of $\geq 1$ episode of $\mathrm{AF}$ per week were asked to participate in this study. Preablation, these patients had experienced $19 \pm 13$ episodes of AF per month. The patients were provided with a patient-activated transtelephonic event recorder for 30 days, a mean of $642 \pm 195$ days after the ablation procedure, and were asked to record and transmit recordings on a daily basis and whenever they felt palpitations. Seven patients $(\mathbf{1 2 \%})$ felt palpitations during the study, although they had not experienced symptoms previously. Each of these 7 patients had an episode of AF documented with the event monitor during symptoms. In these 7 patients, the mean number of episodes per month decreased from $19 \pm 14$ preablation to $3 \pm 1$ postablation $(P<0.001)$. Among the 53 asymptomatic patients, an episode of $\mathrm{AF}$ was captured in $1(2 \%)$ patient during the study period.

Conclusion: Asymptomatic recurrences of AF after an apparently successful catheter ablation procedure for symptomatic paroxysmal AF are infrequent. (J Cardiovasc Electrophysiol, Vol. 15, pp. 920-924, August 2004)
\end{abstract}

atrial fibrillation, pulmonary vein, catheter ablation

\section{Introduction}

With recognition of the critical role of the pulmonary veins in atrial fibrillation $(\mathrm{AF}){ }^{1,2}$ a variety of approaches to radiofrequency catheter ablation of AF have been developed. ${ }^{3-8}$ The clinical efficacy of these ablation procedures has been based in large part on patient-reported symptoms suggestive of AF, often confirmed with an ECG recording. Because most patients undergo an ablation procedure for symptomatic episodes of AF, the absence of symptoms during follow-up has been used as an indicator of freedom from recurrent AF. However, it is well known that patients with symptomatic AF also may have asymptomatic episodes of AF. ${ }^{9,10}$ Therefore, reliance on patient-reported symptoms may result in an overestimate of the efficacy of catheter ablation procedures for AF.

The aim of this study was to investigate the prevalence of asymptomatic episodes of AF in patients who had an appar-

Supported by the Ellen and Robert Thompson Atrial Fibrillation Research Fund.

Address for correspondence: Hakan Oral, M.D., Division of Cardiology, University of Michigan, TC B1 D140, 1500 E. Medical Center Drive, Ann Arbor, MI 48109-0311. Fax: 734-936-7026; E-mail: oralh@umich.edu

Manuscript received 4 February 2004; Accepted for publication 11 March 2004.

doi: 10.1046/j.1540-8167.2004.04055.x ently successful outcome after a catheter ablation procedure for symptomatic paroxysmal AF.

Methods

\section{Study Subjects}

Among 244 consecutive patients with symptomatic paroxysmal AF who underwent a pulmonary vein isolation procedure, 165 were completely asymptomatic at follow-up $\geq 6$ months. Based on a detailed clinical history obtained during a clinical visit prior to the ablation procedure, patients who used to experience $\geq 1$ episode of paroxysmal AF per week were identified among these patients. Subsequently, 60 patients from this pool were randomly chosen and asked to participate in this study. The clinical characteristics of the study subjects and the patient pool from which they were selected were similar (Table 1).

\section{Ablation Procedure}

Pulmonary vein isolation was performed by segmental ostial applications of radiofrequency energy. This technique has been described in detail previously. ${ }^{3,4,11}$ Briefly, after transseptal catheterization, systemic anticoagulation was achieved with intravenous heparin to maintain an activated clotting time of 250 to 350 seconds. A deflectable, decapolar catheter with a distal ring configuration Lasso $^{\mathrm{TM}}$ catheter, Biosense Webster, Diamond Bar, CA, USA) and a deflectable, quadripolar 7-French catheter with 2-5-2 mm 
TABLE 1

Clinical Characteristics

\begin{tabular}{lccc}
\hline & All Patients $(\mathbf{n}=\mathbf{2 4 4})$ & Successful Outcome After Ablation $(\mathbf{n}=\mathbf{1 6 5})$ & Study Subjects $(\mathbf{n}=\mathbf{6 0})$ \\
\hline Age (years) & $53 \pm 11$ & $52 \pm 12$ & $52 \pm 9$ \\
Gender (M/F) & $200 / 44$ & $130 / 35$ & $54 / 6$ \\
Duration (years) & $8 \pm 7$ & $7 \pm 7$ & $8 \pm 8$ \\
Frequency (per month) & $15 \pm 13$ & $15 \pm 14$ & $17 \pm 14$ \\
LVEF & $0.55 \pm 0.04$ & $0.55 \pm 0.05$ & $0.55 \pm 0.02$ \\
LA size (mm) & $40 \pm 5$ & $40 \pm 6$ & $39 \pm 3$ \\
Structural heart disease & 25 & 15 & 5 \\
\hline
\end{tabular}

Data are given mean $\pm \mathrm{SD}$.

There were no significant differences among the groups.

$\mathrm{LA}=$ left atrium; $\mathrm{LVEF}=$ left ventricular ejection fraction.

interelectrode spacing and a 4-mm distal electrode with an embedded thermistor (EP Technologies, Inc., Mountain View, CA, USA) were inserted into the left atrium. A quadripolar electrode catheter was positioned in the coronary sinus. Pulmonary vein isolation was performed by applications of radiofrequency energy at ostial sites that displayed a rapid pulmonary vein tachycardia during $\mathrm{AF}^{4,11}$ or pulmonary vein potentials with the earliest bipolar activation and/or most rapid unipolar intrinsic deflection. ${ }^{12,13}$ Radiofrequency energy was applied at a target temperature of $52^{\circ} \mathrm{C}$ and maximum power of 30 to $35 \mathrm{~W}$ for 20 to 40 seconds. Elimination of all pulmonary vein potentials and complete entrance block into pulmonary veins were the endpoints of ablation.

After the procedure, all patients were anticoagulated with intravenous heparin for 12 to 18 hours. The patients then were discharged and treated with low-molecular-weight heparin for 4 to 5 days and warfarin for at least 6 weeks. A repeat ablation procedure was performed in 36 (15\%) of the 244 patients.

Because a history of typical atrial flutter or inducibility of atrial flutter during the ablation procedure may indicate a high probability of recurrent atrial flutter after pulmonary vein isolation for $\mathrm{AF},{ }^{14}$ cavotricuspid isthmus ablation also was performed in 4 of the 60 patients, as described previously. ${ }^{15}$

\section{Follow-Up}

All patients were seen in an outpatient clinic 1 to 3 months after the catheter ablation procedure and every 3 to 6 months thereafter. All patients who reported palpitations or other symptoms suggestive of an arrhythmia during follow-up were provided with an event monitor to document the cause of their symptoms.

\section{Study Protocol}

The study protocol was approved by the Institutional Review Board at the University of Michigan. All patients provided written informed consent.

At a mean of $642 \pm 195$ days after catheter ablation, the study subjects were provided with a patient-activated, transtelephonic continuous loop recorder (Heart Aide Mini, TZ Medical Inc., Portland, OR, USA) for 30 days and were asked to provide a 3-minute rhythm recording at least once a day. The recordings were acquired randomly throughout the day; there was no predefined hour or portion of the day. In addition, they were asked to provide recordings if any palpitations or symptoms suggestive of AF occurred during the 30 days. The recordings were transmitted by telephone and recorded digitally at a data center. All rhythm recordings were reviewed by an electrophysiologist and categorized as $\mathrm{AF}$, atrial flutter, atrial tachycardia, atrial premature beats, ventricular premature beats, nonsustained ventricular tachycardia, or sinus rhythm.

\section{Statistical Analysis}

Data are expressed as mean \pm SD with confidence intervals (CIs). Categorical variables were compared by Chisquare analysis. The main issue addressed by this study was the prevalence of asymptomatic episodes of AF after a successful ablation procedure in patients with paroxysmal AF. The number of episodes of AF before and after ablation was compared with a paired $t$-test. $\mathrm{P}<0.05$ was considered statistically significant.

\section{Results}

\section{Cardiac Rhythms Recorded}

The 60 study subjects provided rhythm recordings for a mean $25 \pm 8$ days. AF was recorded on $4 \pm 2$ days in 8 (13\%) of the 60 subjects, and atrial flutter was recorded on 2 days in 1 subject $(2 \%)$ who had not undergone ablation of the cavotricuspid isthmus. In the remaining 51 patients, sinus rhythm was recorded on each transmission throughout the study.

\section{Prevalence of Asymptomatic Episodes of AF}

Among the 60 subjects, $1(2 \%)$ was documented to have two asymptomatic episodes of AF during the 30-day monitoring.

\section{Prevalence of Symptomatic Episodes of AF in Previously Asymptomatic Patients}

Among the 60 subjects of this study, 7 (12\%) developed symptoms suggestive of AF after being asymptomatic for $536 \pm 79$ days after the ablation procedure. Electrograms recorded simultaneously with the symptoms confirmed that these episodes were due to recurrent AF. The ventricular rate was $90 \pm 2$ beats/min and $130 \pm 29$ beats/min during asymptomatic and symptomatic episodes of AF, respectively. 


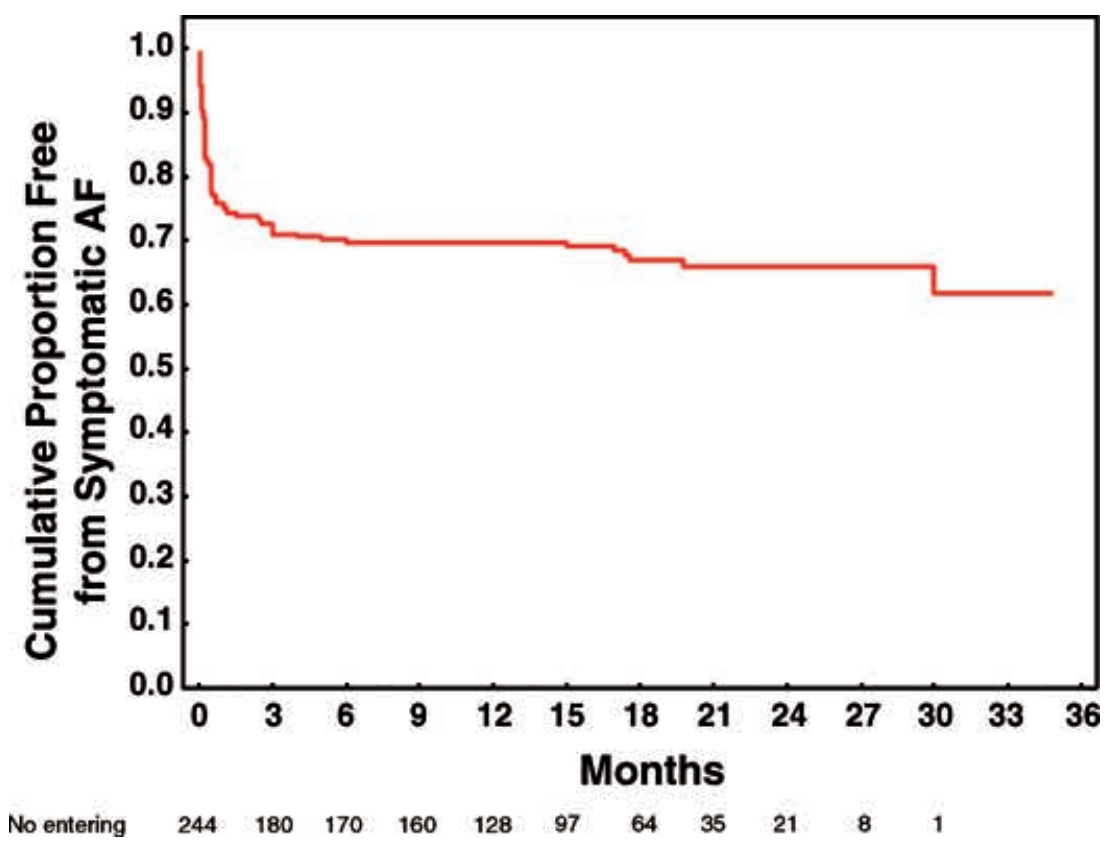

Figure 1. Long-term freedom from symptomatic atrial fibrillation $(A F)$ after pulmonary vein isolation among the 244 patients from whom the study subjects were chosen.

\section{Frequency of Episodes of AF Before and After Ablation}

Prior to the ablation procedure, there were $16 \pm 13$ ( $\pm 95 \%$ CI: 12-21) AF episodes per month among the subjects who were free from recurrent $\mathrm{AF}$ and $19 \pm 14( \pm 95 \%$ CI: 7-32) AF episodes per month among the subjects who had recurrences of $\mathrm{AF}$ after the ablation procedure $(\mathrm{P}=0.6)$.

Among the patients who had a recurrence, $\mathrm{AF}$ was less frequent after the ablation $(3 \pm 1 ; \pm 95 \%$ CI: $2-5)$ episodes per month) than before the ablation $(19 \pm 14$ episodes per month; $\mathrm{P}<0.001$ ).

\section{Freedom from Recurrent AF After PV Isolation}

Among the 60 subjects of this study who had been free from recurrent $\mathrm{AF}$ at 6 months after the ablation, $\mathrm{AF}$ recurred in $8(13 \%), 591 \pm 163$ days after pulmonary vein isolation. Among the study pool of 244 patients from whom the study subjects were chosen, $70 \%$ were free from symptomatic $\mathrm{AF}$ at 6-month follow-up, whereas only $62 \%$ were free from symptomatic AF 30 months after PV isolation (Fig. 1). Among the clinical variables of age, gender, duration and frequency of symptomatic episodes of AF, left ventricular ejection fraction, presence of structural heart disease, and left atrial size, there were no independent predictors of recurrent AF $>180$ days after the ablation procedure.

\section{Discussion}

\section{Main Findings}

The main finding of this study is that asymptomatic episodes of AF are infrequent in patients with symptomatic paroxysmal $\mathrm{AF}$ who undergo pulmonary vein isolation and no longer have symptomatic AF. Also of note is that several patients who initially had an excellent response to pulmonary vein isolation had recurrences of symptomatic $\mathrm{AF}$ as late as 2 years after the ablation procedure.

\section{Asymptomatic and Symptomatic AF}

All of the patients who underwent pulmonary vein isolation in this study had symptomatic AF. A prior study documented that patients with symptomatic paroxysmal AF often also have asymptomatic episodes. ${ }^{10}$ There are two possible explanations for why asymptomatic episodes of AF were found in only one patient in this study. One possibility is that the patients selected to undergo catheter ablation were particularly symptomatic and less likely than most patients to have asymptomatic episodes of AF. Another possibility is that the patients in this study had both symptomatic and asymptomatic episodes of AF preablation, and that pulmonary vein isolation was equally effective in eliminating the symptomatic and asymptomatic episodes. In theory, the only possible reason that catheter ablation would eliminate symptomatic AF more effectively than asymptomatic $\mathrm{AF}$ would be a placebo effect of the procedure. Because prolonged monitoring to detect asymptomatic episodes of AF was not performed before catheter ablation, the actual explanation for why asymptomatic episodes of AF were infrequent after ablation is unknown.

Patients with paroxysmal AF may become symptomatic because of an abrupt increase in heart rate. If the ventricular rate is well controlled, there may be little perceivable change in the ventricular rate and patients may remain asymptomatic. Because none of the patients in this study were being treated with antiarrhythmic drugs (including negative dromotropic agents), the average ventricular rate during recurrent episodes of $\mathrm{AF}$ was rapid. This may explain why 7 of the 8 patients with recurrent $\mathrm{AF}$ in the course of this study were symptomatic during the AF. The average ventricular rate in the single patient who had asymptomatic AF was only 90/minute, which perhaps explains why the patient was unaware of the episode.

Of note is that seven patients who had been asymptomatic for $>6$ months developed symptomatic $\mathrm{AF}$ once they received 
an event monitor and began participation in this study. This may have simply been due to coincidence, but also it is possible that the patients became more aware of mild ongoing symptoms during participation in the study.

\section{Late Recurrences of AF}

First recurrences of AF occurred as late as 2 years after pulmonary vein isolation. One possible explanation for late recurrences of AF would be the recovery of conduction over a previously ablated pulmonary vein fascicle. However, recovery of conduction usually occurs early after an ablation procedure, and it seems unlikely that conduction through an ablated fascicle would resume 2 years postablation. A possible explanation for late recurrences of $\mathrm{AF}$ is the emergence of arrhythmogenic foci outside of the pulmonary veins. However, it is important to note that the mechanism of AF often is multifactorial, ${ }^{16}$ and there may have been progressive electroanatomic remodeling in the left atrium itself as a result of aging or underlying structural disease. Late recurrences of AF may underscore the importance of left atrial substrate modification, which may render AF less likely to perpetuate regardless of the primary mechanism.

\section{Prior Studies}

A prior study used loop recorder transmissions every 2 weeks for 6 to 9 months and demonstrated that asymptomatic AF occurred in $13 \%$ of patients treated with azimilide and $18 \%$ of patients receiving a placebo. ${ }^{9}$ Most recurrences of AF occurred within a few weeks after restoration of sinus rhythm. In the present study, patients needed to be asymptomatic for at least 6 months after ablation. A recent study demonstrated that asymptomatic recurrent episodes of $\mathrm{AF}$ were infrequent in patients who were asymptomatic after ablation, whereas patients who had symptomatic recurrences were more likely to have asymptomatic recurrences. ${ }^{17}$

Perception of symptoms may differ between patients with paroxysmal and persistent $\mathrm{AF}$, and patients with persistent AF may be less likely to identify an episode of recurrent AF once sinus rhythm has been restored. Consistent with this possibility, a prior report demonstrated that the prevalence of asymptomatic episodes of AF among patients with paroxysmal AF was $4 \%,{ }^{10,18}$ which is markedly lower than the reported prevalence in patients converted out of persistent AF. ${ }^{9}$

\section{Study Limitations}

A limitation of this study is that the event monitors were patient activated, not automatic. It is possible that some episodes of asymptomatic AF were undetected, particularly if they were brief in duration or limited to periods of sleep. Additional studies using automatic recordings obtained with implanted or wearable monitors will be necessary to more accurately define the prevalence of asymptomatic AF after catheter ablation.

The findings of this study apply only to patients with symptomatic paroxysmal AF who undergo pulmonary vein isolation. Although asymptomatic late recurrences of $\mathrm{AF}$ were infrequent in these patients, this may not be the case in patients who are less symptomatic, in patients with persistent AF, or in patients who undergo other types of ablation procedure for AF.

\section{Conclusion}

When pulmonary vein isolation is performed in patients with symptomatic paroxysmal AF, the elimination of symptoms in the absence of antiarrhythmic drug therapy appears to provide a fairly accurate indicator of efficacy. Although asymptomatic episodes may occur late after pulmonary vein isolation, the majority of $\mathrm{AF}$ recurrences are associated with symptoms. Because the first recurrence of AF may occur $>2$ years after pulmonary vein isolation, a long period followup is necessary to define the long-term efficacy of ablation procedures for AF.

\section{References}

1. Haissaguerre M, Jais P, Shah DC, Takahashi A, Hocini M, Quiniou G, Garrigue S, Le Mouroux A, Le Metayer P, Clementy J: Spontaneous initiation of atrial fibrillation by ectopic beats originating in the pulmonary veins. N Engl J Med 1998;339:659-666.

2. Oral H, Ozaydin M, Tada H, Chugh A, Scharf C, Hassan S, Lai S, Greenstein R, Pelosi F Jr, Knight BP, Strickberger SA, Morady F: Mechanistic significance of intermittent pulmonary vein tachycardia in patients with atrial fibrillation. J Cardiovasc Electrophysiol 2002;13:645650 .

3. Haissaguerre M, Shah DC, Jais P, Hocini M, Yamane T, Deisenhofer I, Chauvin M, Garrigue S, Clementy J: Electrophysiological breakthroughs from the left atrium to the pulmonary veins. Circulation 2000; 102:2463-2465.

4. Oral H, Knight BP, Tada H, Ozaydin M, Chugh A, Hassan S, Scharf C, Lai SW, Greenstein R, Pelosi F Jr, Strickberger SA, Morady F: Pulmonary vein isolation for paroxysmal and persistent atrial fibrillation. Circulation 2002;105:1077-1081.

5. Pappone C, Oreto G, Lamberti F, Vicedomini G, Loricchio ML, Shpun S, Rillo M, Calabro MP, Conversano A, Ben-Haim SA, Cappato R, Chierchia S: Catheter ablation of paroxysmal atrial fibrillation using a 3D mapping system. Circulation 1999;100:1203-1208.

6. Pappone C, Oreto G, Rosanio S, Vicedomini G, Tocchi M, Gugliotta F, Salvati A, Dicandia C, Calabro MP, Mazzone P, Ficarra E, Di Gioia C, Gulletta S, Nardi S, Santinelli V, Benussi S, Alfieri O: Atrial electroanatomic remodeling after circumferential radiofrequency pulmonary vein ablation: Efficacy of an anatomic approach in a large cohort of patients with atrial fibrillation. Circulation 2001;104:25392544.

7. Marrouche NF, Dresing T, Cole C, Bash D, Saad E, Balaban K, Pavia SV, Schweikert R, Saliba W, Abdul-Karim A, Pisano E, Fanelli R, Tchou P, Natale A: Circular mapping and ablation of the pulmonary vein for treatment of atrial fibrillation: Impact of different catheter technologies. J Am Coll Cardiol 2002;40:464-474.

8. Mangrum JM, Mounsey JP, Kok LC, DiMarco JP, Haines DE: Intracardiac echocardiography-guided, anatomically based radiofrequency ablation of focal atrial fibrillation originating from pulmonary veins. J Am Coll Cardiol 2002;39:1964-1972.

9. Page RL, Tilsch TW, Connolly SJ, Schnell DJ, Marcello SR, Wilkinson WE, Pritchett EL: Asymptomatic or "silent" atrial fibrillation: Frequency in untreated patients and patients receiving azimilide. Circulation 2003;107:1141-1145.

10. Page RL, Wilkinson WE, Clair WK: Asymptomatic arrhythmias in patients with symptomatic paroxysmal atrial fibrillation and paroxysmal supraventricular tachycardia. Circulation 1994:224-227.

11. Oral H, Knight BP, Ozaydin M, Chugh A, Lai SW, Scharf C, Hassan S, Greenstein R, Han JD, Pelosi F Jr, Strickberger SA, Morady F: Segmental ostial ablation to isolate the pulmonary veins during atrial fibrillation: Feasibility and mechanistic insights. Circulation 2002;106:12561262 .

12. Tada H, Oral H, Wasmer K, Greenstein R, Pelosi F Jr, Knight BP, Strickberger SA, Morady F: Pulmonary vein isolation: Comparison of bipolar and unipolar electrograms at successful and unsuccessful ostial ablation sites. J Cardiovasc Electrophysiol 2002;13:13-19.

13. Tada H, Oral H, Knight BP, Ozaydin M, Chugh A, Scharf C, Hassan S, Greenstein R, Pelosi F Jr, Strickberger SA, Morady F: Randomized comparison of bipolar versus unipolar plus bipolar recordings during segmental ostial ablation of pulmonary veins. J Cardiovasc Electrophysiol 2002;43:851-856. 
14. Scharf C, Veerareddy S, Ozaydin M, Chugh A, Hall B, Cheung P, Good E, Pelosi F, Morady F, Oral H: Clinical significance of inducible atrial flutter during pulmonary vein isolation in patients with atrial fibrillation. J Am Coll Cardiol 2004;43:2057-2062.

15. Ozaydin M, Tada H, Chugh A, Scharf C, Lai SW, Pelosi F, Knight BP, Morady F, Oral H: Atrial electrogram amplitude and efficacy of cavotricuspid isthmus ablation for atrial flutter. Pacing Clin Electrophysiol 2003;26:1859-1863.

16. Allessie MA, Boyden PA, Camm AJ, Kleber AG, Lab MJ, Legato MJ, Rosen MR, Schwartz PJ, Spooner PM, Van Wagoner DR, Waldo
AL: Pathophysiology and prevention of atrial fibrillation. Circulation 2001;103:769-777.

17. Pappone C, Santinelli V, Manguso F, Vicedomini G, Gugliotta F, Augello G, Mazzone P, Tortoriello V, Landoni G, Zangrillo A, Lang C, Tomita T, Mesas C, Mastella E, Alfieri O: Pulmonary vein denervation enhances long-term benefit after circumferential ablation for paroxysmal atrial fibrillation. Circulation 2004;109:327-334.

18. Lin HJ, Wolf PA, Benjamin EJ, Belanger AJ, D’Agostino RB: Newly diagnosed atrial fibrillation and acute stroke. The Framingham Study. Stroke 1995;26:1527-1530. 